\title{
Regional stress field in Yunnan revealed by the focal mechanisms of moderate and small earthquakes
}

\author{
JianHui Tian', Yan Luo', and Li Zhao ${ }^{2^{*}}$ \\ ${ }^{1}$ Key Laboratory of Earthquake Prediction, Institute of Earthquake Forecasting, China Earthquake Administration, Beijing 100036, China; \\ ${ }^{2}$ School of Earth and Space Sciences, Peking University, Beijing 100871, China
}

\begin{abstract}
We determined focal mechanism solutions of 627 earthquakes of magnitude $M \geq 3.0$ in Yunnan from January 2008 to May 2018 by using broadband waveforms recorded by 287 permanent and temporary regional stations. The results clearly revealed predominantly strike-slip faulting characteristics for earthquakes in Yunnan, with focal depths concentrated in the top $10 \mathrm{~km}$ of the crust. The earthquake mechanisms obtained were combined with the global centroid moment tensor solutions of 80 additional earthquakes from 1976 to 2016 to invert for the regional variations of stress field orientation by using a damped regional-scale stress inversion scheme. Results of the stress field inversion confirmed that the Yunnan region is under a strike-slip stress regime, with both maximum and minimum stress axes being nearly horizontal. The maximum compressional axes are primarily oriented in a northwest-southeast direction, and they experience a clockwise rotation from north to south, whereas the maximum extensional axes are oriented largely northeast-southwest. The maximum compressional axes are in line with the global positioning system-inferred horizontal velocity field and the southeastward escape of the Sichuan-Yunnan Rhombic Block, whereas the maximum extensional axes are consistent with anisotropy derived from SKS splitting. Against the strike-slip background, normal faulting stress regimes can be seen in the Tengchong volcanic area as well as in other areas with complex crisscrossing fault zones.
\end{abstract}

Keywords: earthquake focal mechanism; stress field inversion; principle stresses; Yunnan region

Citation: Tian, J. H., Luo, Y., and Zhao, L. (2019). Regional stress field in Yunnan revealed by the focal mechanisms of moderate and small earthquakes. Earth Planet. Phys., 3(3), 243-252. http://doi.org/10.26464/epp2019024

\section{Introduction}

Yunnan is located in the southern segment of the north-south seismic belt of China. From west to east, it spans the Yunnan-Myanmar-Thailand Block (YMTB), the Indo-China Block (ICB), and the Yangtze Block (YTB), which is part of the South China Block (Shen CY et al., 2002; see Figure 1). The YMTB is further divided into the Tengchong-Baoshan and Baoshan-Puer blocks (Huang FG et al., 2010). The YTB consists of the Sichuan-Yunnan Rhombic Block (SYRB) and the Eastern Yunnan Block (EYB) separated by the Xiaojiang Fault Zone (XJFZ). The Yunnan region is mainly influenced by the collision between the Indian and Eurasian plates, which results in the rise of the Tibetan Plateau and subsequent movement in its eastern margin. The resistance of the YTB in the east causes the southeastward escape of the SYRB and displacement along the Red River Fault Zone (RRFZ). A number of deep faults in the Yunnan area, such as the Zhaotong-Lianfeng Fault Zone (ZLFZ), Anninghe Fault Zone (ANHFZ), and Zemuhe Fault Zone (ZMHFZ), are under complex tectonic stresses that form the northern continuations of the XJFZ; the Jinshajiang Fault Zone (JSJFZ) extending north from the RRFZ; the Lijiang-Xiaojinhe Fault Zone (LXFZ) crosscutting the SYRB from the JSJFZ to the ANHFZ;

Correspondence to: L. Zhao, lizhaopku@pku.edu.cn

Received 29 JAN 2019; Accepted 02 MAR 2019.

Accepted article online 02 APR 2019.

C 2019 by Earth and Planetary Physics. and the Lancangjiang Fault Zone (LCJFZ) and Nujiang Fault Zone (NJFZ) further west. It is one of the most seismically active regions in the world, with frequent earthquakes of moderate and large magnitudes (Figure 1). From January 1970 to May 2018, a total of 393 earthquakes of magnitude $M \geq 5$ occurred in this area, among which 65 were $M \geq 6$ and 12 were $M \geq 7$. Most of the strong earthquakes have been located at the junctions of the fault zones. Hence, Yunnan has long been an important monitoring area of earthquake hazards and a typical area for studying the seismogenic background and dynamic process of continental earthquakes. In recent years, with the increase in the deployment of digital seismic stations, more and more high-resolution broadband waveform records have become available for the study of focal mechanism solutions and the regional stress field in Yunnan. One of the purposes of this work is to use the waveform records to determine the focal mechanisms of moderate and large earthquakes in Yunnan and its surrounding regions, and to further investigate the stress environment and the seismogenic mechanism of large earthquakes.

Regional tectonic movements regulate the changes in the regional stress field, which in turn characterize the faulting patterns of local earthquakes. Therefore, studying the focal mechanism pattern of earthquakes in a region can be an effective tool for investigating the regional stress field. Many previous efforts have been made to study the tectonic stress field of the Yunnan region by 


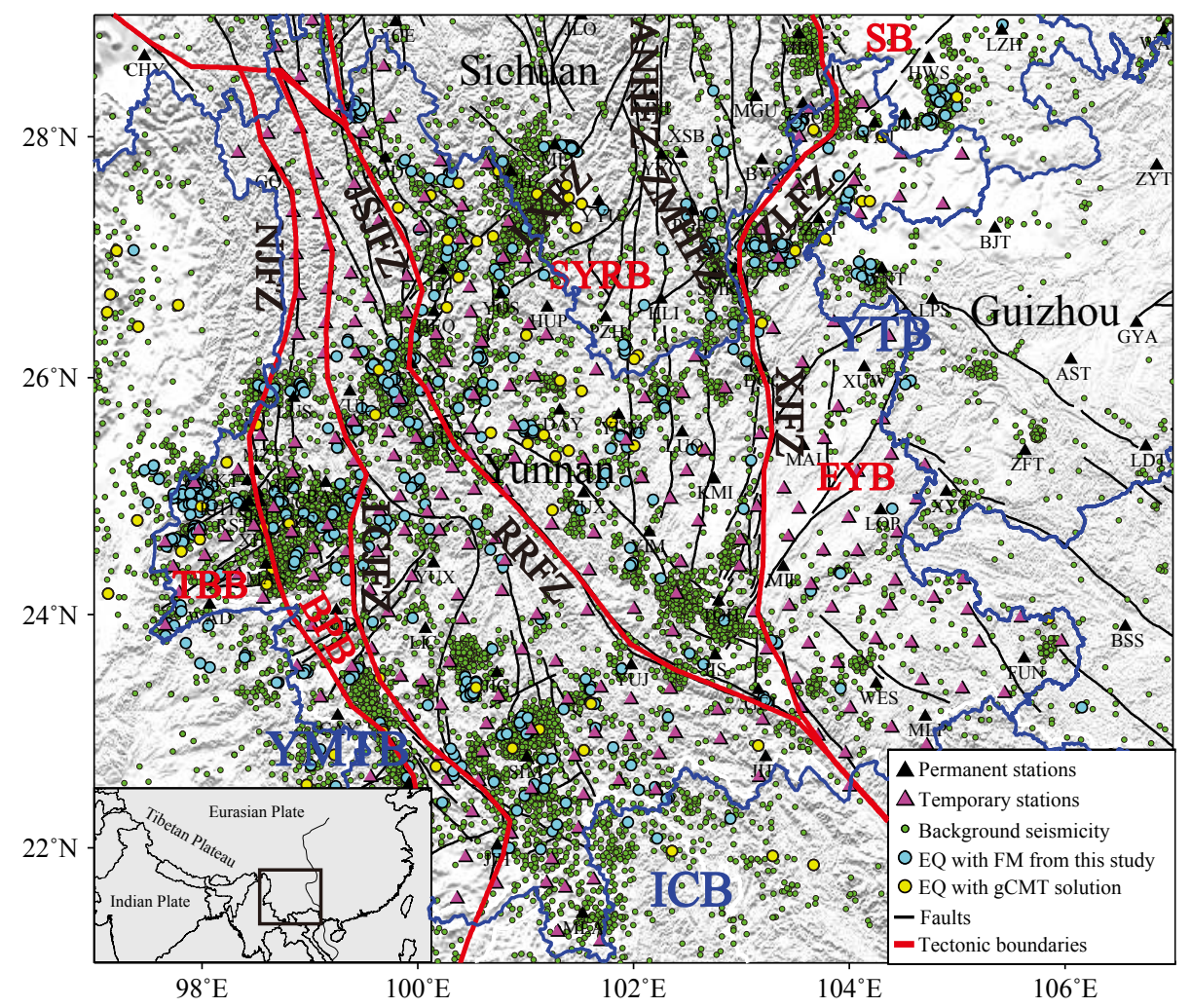

Figure 1. Tectonic background of the Yunnan region and distribution of earthquakes and seismic stations. The black and magenta triangles are locations of the permanent and temporary stations, respectively, used in this study. The small green circles show the background seismicity from January 1970 to May 2018. The larger blue and yellow circles show epicenters of earthquakes whose focal mechanisms were used to study the regional stress field in this study. The focal mechanisms for the blue circles were determined in this study, whereas the focal mechanisms for the yellow circles were taken from the gCMT catalog. The thin black lines are faults, and the thick red lines are boundaries between active tectonic blocks. The blue lines are provincial and national boundaries. The abbreviations for the major active tectonic blocks and fault zones are as follows: YTB: Yangtze Block; ICB: Indo-China Block; YMTB: Yunnan-Myanmar-Thailand Block; SB: Sichuan Basin; SYRB: Sichuan-Yunnan Rhombic Block; EYB: Eastern Yunnan Block; TBB: Tengchong-Baoshan Block; BPB: Baoshan-Puer Block; ZLFZ: Zhaotong-Lianfeng Fault Zone; ANHFZ: Anninghe Fault Zone; ZMHFZ: Zemuhe Fault Zone; XJFZ: Xiaojiang Fault Zone; LXFZ: Lijiang-Xiaojinhe Fault Zone; JSJFZ: Jinshajiang Fault Zone; RRFZ: Red River Fault Zone; LCJFZ: Lancangjiang Fault Zone; and NJFZ: Nujiang Fault Zone. The inset map shows the location of the region under study.

using earthquake focal mechanism solutions (e.g. Xu ZH et al., 1987; Wu JP et al., 2004; Qian XD et al., 2011; Zhao L et al., 2013; Luo J et al., 2016; Xu ZG et al., 2016; Sun YJ et al., 2017). The modern tectonic stress field in southwestern China has also been studied by inversion of the fault-slip directions (Xie FR et al., 1993). In addition, regional crustal movement has been revealed by the results of shear-wave splitting analyses (e.g. Shi YT et al., 2012) as well as global positioning system (GPS) observations (Qiao XJ et al., 2004; Zhao B et al., 2015). Most of the previous studies on the stress field in Yunnan have been based on solutions from the global centroid moment tensor (gCMT) catalog or focal mechanisms derived from the polarity of the initial P-wave motion for moderate and strong earthquakes. The orientations of the $P$ and $T$ axes from the focal mechanism solutions have then been used to further constrain the tectonic stress field in Yunnan and the surrounding regions. Owing to the limited number of earthquake focal mechanisms, most of the previous efforts have focused only on relatively large-scale patterns, which are insufficient for detailed analysis of the stress field variations on a smaller scale and with a higher resolution. For example, Zhao L et al. (2013) used the cut-and-paste (CAP) method to determine the focal mechan- isms of 174 earthquakes with $M>3.5$ from January 2008 to March 2011 in Yunnan and combined them with $113 \mathrm{gCMT}$ solutions to invert for the stress field. Xu ZG et al. (2016) used 684 focal mechanisms, which included previously published solutions and their own solutions of 343 earthquakes with $M>3.0$ in the Sichuan-Yunnan region from August 2011 to December 2013 to invert for the stress field in the Sichuan-Yunnan region. The results of Zhao L et al. (2013) and Xu ZG et al. (2016) agreed in the general pattern of a predominant strike-slip stress field in Yunnan. However, the small-scale patterns, especially in the non-strike-slip stress regions, were not consistent. Here, we have taken advantage of the increased number of broadband seismic records from densely populated stations recently deployed in the Yunnan region to substantially augment the earthquake focal mechanism catalog. We have then used the focal mechanisms to invert for the regional stress field with an increased resolution. This procedure revealed detailed characteristics of the small-scale stress field variation and enhanced our understanding of the relationship between stress changes on seismic faults and the occurrence of strong earthquakes. 


\section{Seismic Data}

In this study, we used the broadband waveform records from 87 permanent and 200 temporary stations in Yunnan and the surrounding areas. Figure 1 shows the distribution of the seismic stations. The three-component records were used to determine the focal mechanisms of 627 local earthquakes of magnitudes $M>3.0$ from January 2008 to May 2018 by using the CAP method (Zhao LS and Helmberger, 1994; Zhu LP and Helmberger, 1996). We also augmented our focal mechanism catalog by including the gCMT solutions of 80 additional earthquakes. Focal mechanisms of the 707 earthquakes as well as the orientations of the $\mathrm{P}$ and $\mathrm{T}$ axes were analyzed. These 707 focal mechanisms were then used to determine the regional stress field by using the damped regionalscale stress inversion method of Hardebeck and Michael (2006). Here we discuss the spatial pattern of the stress field and its relationship with active tectonics and strong earthquakes in the Yunnan region based on the inversion results.

\subsection{Determination of Earthquake Focal Mechanisms}

The focal mechanism is one of the primary mechanical features of earthquake sources. Over the past few decades, a variety of methods have been developed to determine the focal mechanisms by using different aspects of the seismic records, such as the polarity of the initial P-wave motion, the ratio of $\mathrm{P}$ - and S-wave amplitudes, and the waveforms of different portions of the seismograms. Among the different approaches, waveform inversion provides the most robust solutions and has now been universally adopted in earthquake source studies. In this study, we used the CAP method first proposed for double-couple solutions by Zhao LS and Helmberger (1994) and later refined by Zhu LP and Helmberger (1996). Zhu LP and Ben-Zion (2013) extended the method to gCAP, which considers the general moment tensor source, including both the double-couple and non-double-couple components. This method decomposes the three-component seismograms at a given station into shorter-period $\mathrm{P}_{\mathrm{nl}}$ waves and longer-period surface waves, and it searches for the source parameters, including the focal depth and full moment tensor, that provide the best-fitting synthetic waveforms. By fitting the $P_{n l}$ waves and surface waves independently, the CAP method effectively prevents the inversion result from being dominated by the surface waves, which have much larger amplitudes than the $P_{n l}$ waves. The use of multiwindow waveforms with properly assigned relative weightings in the inversion enables the CAP method to yield reliable solutions even when the station distribution or the velocity model is not ideal. This method has been applied effectively in studies of moderate and small earthquakes of magnitude $M>3.0$ (e.g., Lü J et al., 2008; Zheng Y et al., 2009; Long F et al., 2010; Luo Y et al., 2010; Zhao L et al., 2013).

In this study, we used the CAP method and obtained the doublecouple focal mechanism solutions of 627 earthquakes in Yunnan from January 2008 to May 2018. The results are shown in Figure 2a. To gain a more complete collection of focal mechanisms, we also retrieved the focal mechanism solutions of 80 earthquakes from the gCMT catalog, as shown in Figure 2b.

The focal mechanism solutions in Figure 2 clearly show that earthquakes throughout Yunnan are predominantly strike-slip (defined in this study by a rake angle less than $35^{\circ}$ from horizontal), with scattered normal (rake angle less than $35^{\circ}$ from down-dip), thrust (rake angle less than $35^{\circ}$ from up-dip), and mixed-type (rake angles $35^{\circ}$ or more from horizontal or dip) faulting events. Normal-faulting earthquakes in the region mainly occur in western and northwestern Yunnan. Thrust-faulting events are largely distributed in the border areas, especially in the northeast corner and southwest of the RRFZ. Figure 3 shows the centroid depth of the earthquakes determined in this study as well as from the gCMT catalog. Among the 627 earthquakes determined in this study, the maximum focal depth was $38 \mathrm{~km}$ (Figure 3a). Most of the depths (a total of 510) were shallower than $15 \mathrm{~km}$, with a heavy concentration between 5 and $10 \mathrm{~km}$ (348). Ninety-six earthquakes had
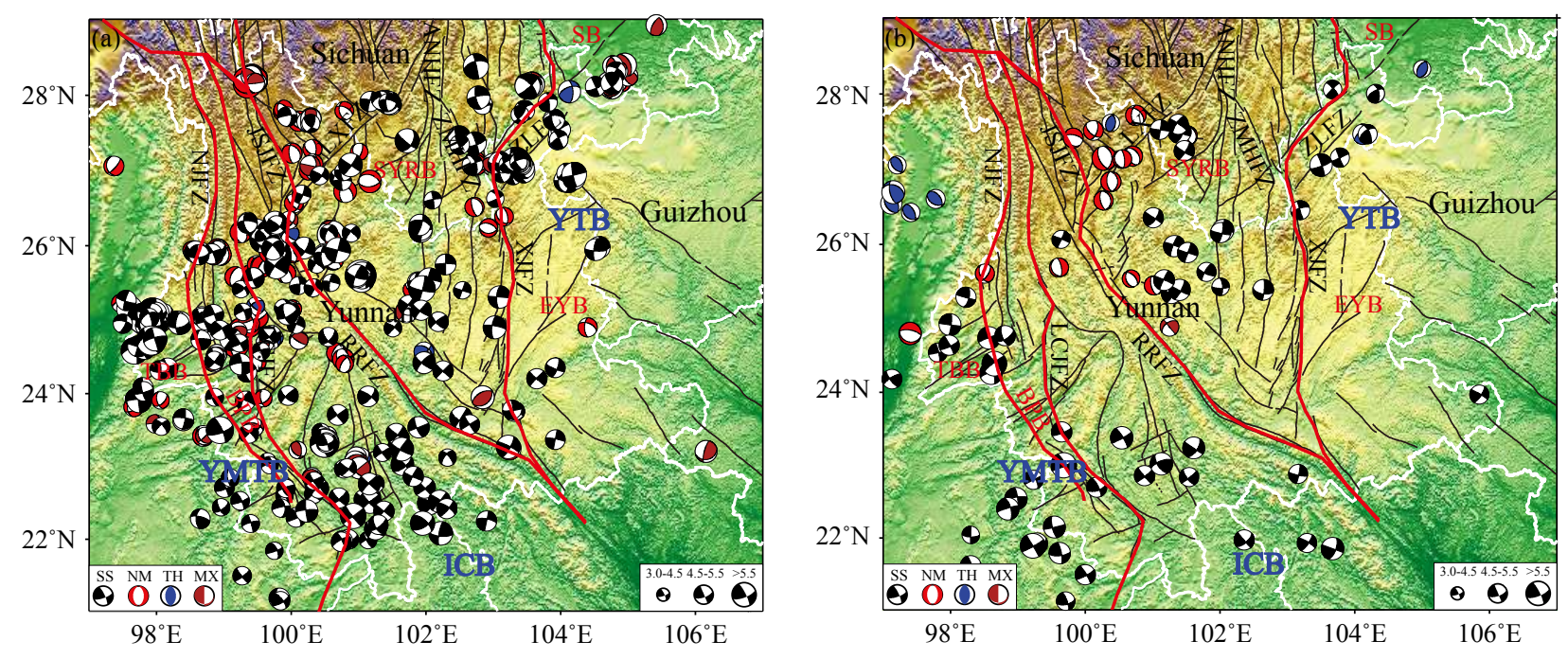

Figure 2. (a) Focal mechanism solutions of the 627 earthquakes determined by the cut-and-paste method in this study. The size of the focal sphere indicates the moment magnitude of an earthquake, whereas the color indicates the faulting type, with black, red, blue, and brown representing strike-slip, normal, thrust, and mixed types, respectively (see text for definitions of faulting types). The abbreviations for the major active tectonic blocks and fault zones are the same as in Figure 1. (b) Same as (a) but for the 80 solutions retrieved from the gCMT catalog. 

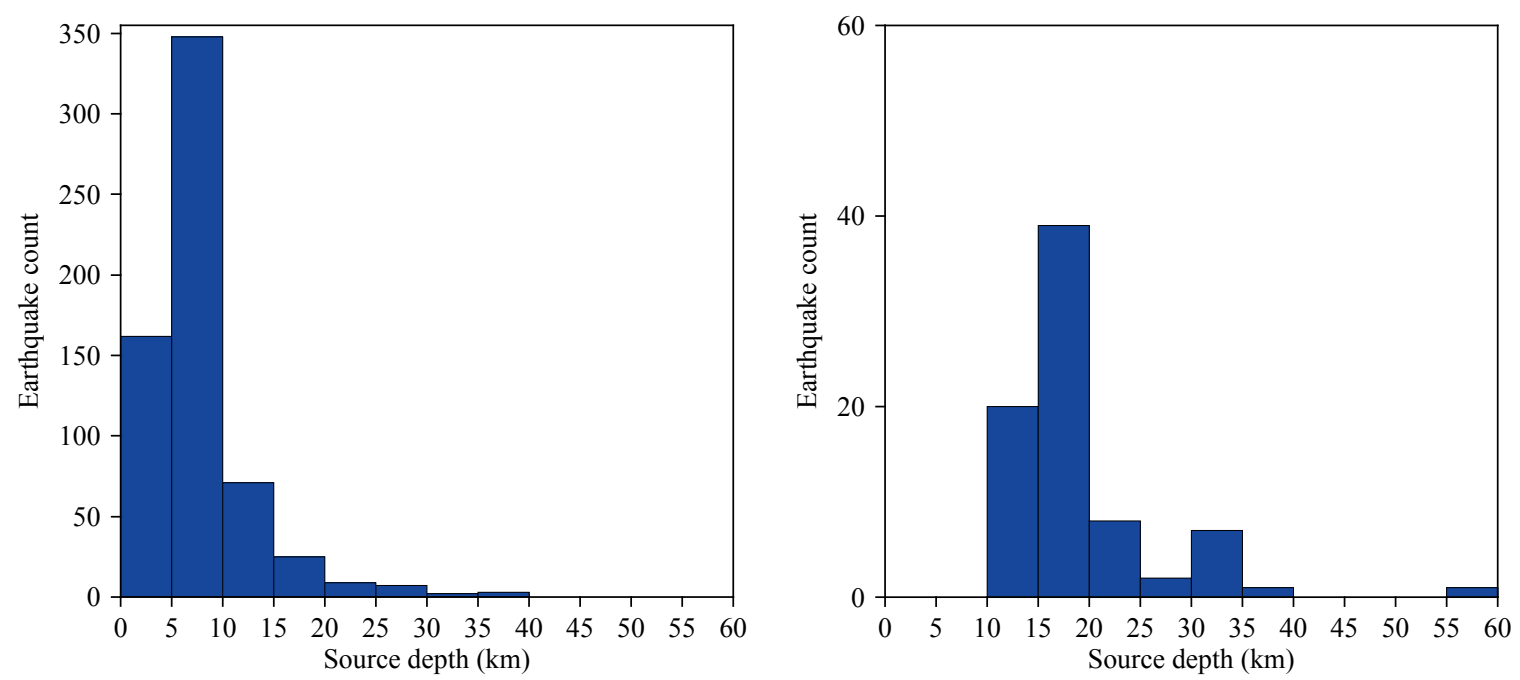

Figure 3. (a) Histogram of the source centroid depths of the 627 earthquakes determined in this study. (b) Histogram of the centroid depths of the 80 earthquakes from the gCMT catalog.

depths between 10 and $20 \mathrm{~km}, 16$ earthquakes were within $\sim 20-30 \mathrm{~km}$, and only 5 earthquakes were below a depth of $30 \mathrm{~km}$. Most of the centroid depths from the gCMT solutions were also greater than $20 \mathrm{~km}$, with a major concentration within $\sim 15-20$ $\mathrm{km}$. The CAP method uses waveforms of $P_{n l}$ waves, which contain information on the depth phases, such as $\mathrm{SP}$ and $\mathrm{pP}$, and provide better constraints on the depths of the earthquakes.

The geographical depth distributions in Figure 4 show that the earthquakes in the southwest corner of the study area (in Myanmar) and in the SYRB occurred at relatively greater depths. This suggests that the seismogenic layer in the crust of the Yunnan region is more than $\sim 20 \mathrm{~km}$, which is consistent with the results of Zhao L et al. (2013).

To display the spatial pattern of the earthquake faulting mechanisms in the Yunnan region more clearly, we plotted in Figure 5 the horizontal projections of the $\mathrm{P}$ and $\mathrm{T}$ axes of the 707 focal mechanisms in Figure 2. The entire region was obviously under a strikeslip environment, with both $\mathrm{P}$ and $\mathrm{T}$ axes being more or less horizontal. A clear clockwise rotation of the axes also occurred from north to south. The $P$ axes in the northern part of the study region in SYRB and EYB were mostly oriented in the west-northwest direction. They changed to northwest along the XJFZ in southeastern SYRB and EYB, to the north-northwest and almost northsouth in the southernmost SYRB and across the RRFZ in the ICB, and finally to slightly northeast-southwest in the BSB and TBB in southwestern Yunnan. This pattern agrees with those in previous studies (Xu ZH et al., 1987; Zhao L et al., 2013) in the Yunnan region.

The eastern Yunnan region (EYB in Figure 5) is mostly located to the east of the XJFZ. In addition to the predominant strike-slip faulting earthquakes, a few normal and reverse faulting events are also present. The $\mathrm{P}$ axes are predominantly oriented in the northwest direction, whereas the directions of the T axes show significant lateral variation. In the northeast corner region of Yunnan, the $\mathrm{T}$ axes are in a north-northeast direction with a relatively large plunge, resulting in reverse-faulting events (Figure 4) showing strong east-west compression at the boundary between the lower elevation Sichuan and Guizhou and the mountain range in the west in Yunnan. In recent years, several moderate earthquakes with strike-slip mechanisms have occurred on the ZLFZ, and a few thrust events have occurred at the northern end of the ZLFZ, where the trend of the fault zone turns from northeast to north. The August 3, 2014, Mw6.4 Ludian earthquake occurred in the western section of the ZLFZ on a north-northwest-trending fault with horizontal $\mathrm{P}$ and $\mathrm{T}$ axes oriented in the northwest and northeast directions, respectively.

In our study region, the SYRB is bounded by the JSJFZ and RRFZ in the west and the XJFZ in the east. Earthquakes in this region are mainly strike-slip, with largely horizontal $P$ axes oriented in the north-northwest direction and $\mathrm{T}$ axes in the northeast to an almost east-west direction. However, along the XJFZ near the border between Yunnan and Sichuan, the focal mechanism solutions change from strike-slip to normal faulting. The $P$ axes change from nearly horizontal to having a relatively high plunge, whereas the $T$ axes turn from almost east-west to northeast and northnortheast. Southward along the XJFZ, earthquakes change to strike-slip faulting. Wang LL et al. (2016) reported that the average slip rate of the ZMHFZ is $5.19 \mathrm{~mm} / \mathrm{a}$, whereas the strike-slip rates along the XJFZ are $5.97,7.19$, and $5.30 \mathrm{~mm} / \mathrm{a}$, respectively, in the northern, middle, and southern sections. The presence of normal-faulting earthquakes may be related to the differential slip rates along the ZMHFZ and the northern section of the XJFZ. The transition from normal faulting to strike-slip is also consistent with the slip rate in the middle to south sections of the XJFZ.

Southwest Yunnan is surrounded by the RRFZ and the LCJFZ. This region spans the YMTB and the ICB. The predominant faulting type is still mainly strike-slip, with a small number of reverse- and normal-faulting events. The $P$ axes of earthquakes in this region are rotated from north-northwest to nearly north-south, and the T axes also rotate accordingly. This pattern agrees with the observations of Qian XD et al. (2011) and Zhong JM and Cheng WZ (2006).

Western Yunnan contains the region west of the LCJFZ. The main 

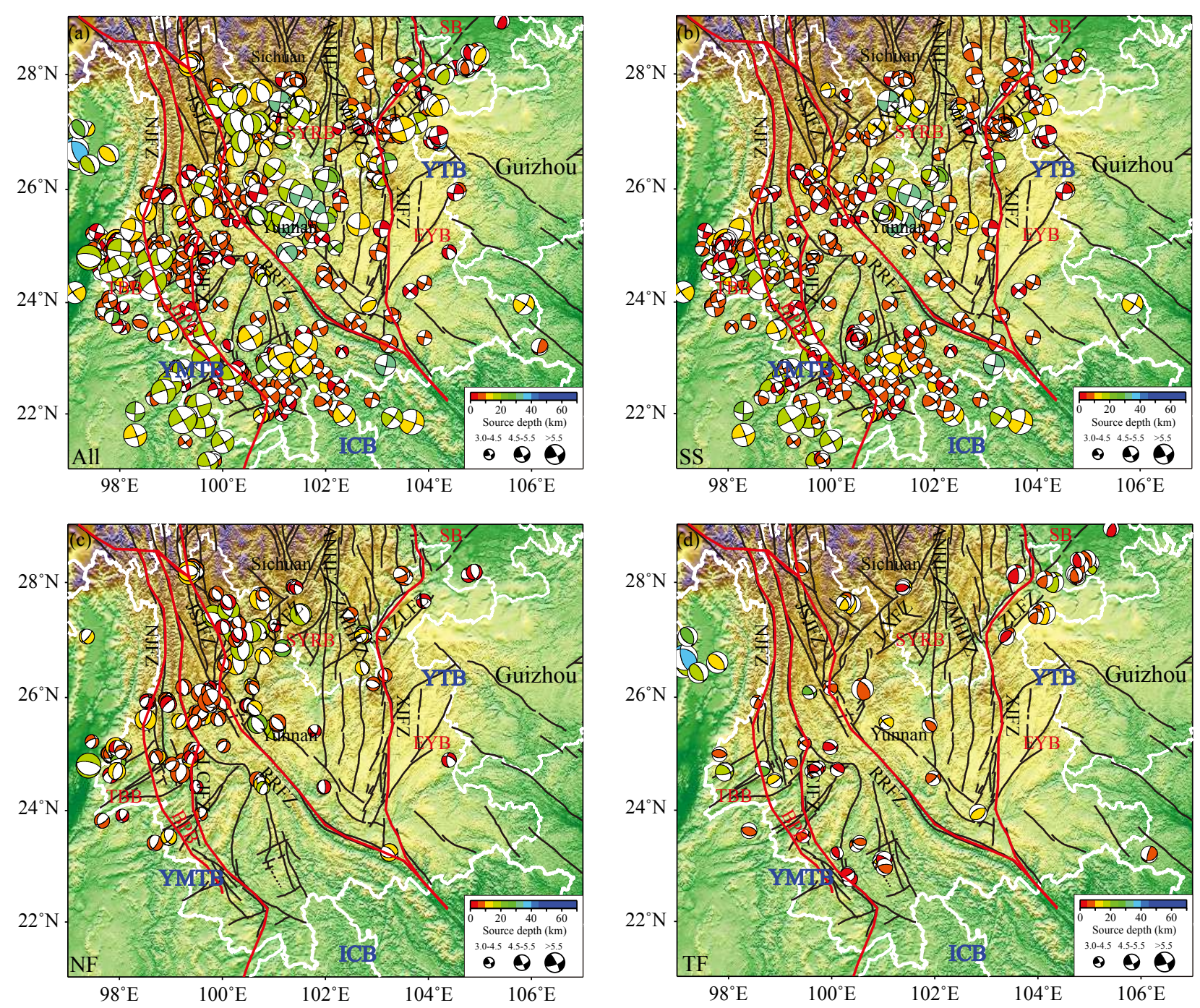

Figure 4. (a) Geographical distribution of the $707 \mathrm{focal}$ mechanisms ( 627 from this study plus 80 from the gCMT catalog) used in this study, with source centroid depths shown by the color of the beachballs. The size of the beachballs indicates the magnitude. The abbreviations for the major fault zones and tectonic blocks are the same as in Figure 1. (b)-(d) Same as (a) but for strike-slip, normal, and thrust earthquakes, respectively.

faulting types of earthquakes in this area are strike-slip and normal-faulting events, with their $P$ axes further rotated from a northsouth to slightly northeast direction. Near the Tengchong volcanic region, earthquakes with normal-faulting mechanisms have $T$ axes oriented in a nearly east-west direction.

In northwestern Yunnan, the major tectonic features are the northwest-trending JSJFZ and the northeast-trending LXFZ. Earthquakes in this area have different faulting types. The proportions of strike-slip and normal-faulting events are about equal. A number of normal-faulting events appear in the very northwest corner of our study area near the JSJFZ. The orientations of the P and T axes change drastically. Overall, the directions of $P$ axes are nearly vertical and those of the T axes are near horizontal, with a northnortheast orientation, which indicates that the area is undergoing strong extension. In the region along the southern section of the LXFZ, the focal mechanisms change from strike-slip to the normalfaulting type, and the orientations of the $P$ axes change from nearly horizontal to nearly vertical, whereas the $T$ axes become nearly horizontal, with an east-northeast direction.

\subsection{Tectonic Stress Field Inversion}

The focal mechanism solution is one of the most reliable datum sources that can be used to infer the stress field at depth. Indeed, since the work of McKenzie (1969), which first made a quantitative connection between the earthquake mechanism and the stress field, fault plane solutions have been widely used to determine the stress field (e.g., Angelier, 1979, 1984; Gephart and Forsyth, 1984; Michael, 1984, 1987). The inversion of the stress field in a location by using a number of local earthquakes is based on three assumptions: (1) that all the earthquakes occur on existing fault planes with diverse orientations, (2) that the slip directions of all the earthquakes are parallel to the directions of the tangential tractions on the fault planes, and (3) that the local stress field is the same for all the earthquakes used. The relationship between the component of the sliding vector and the stress tensor vector can then be expressed as (Michael, 1984)

$$
\hat{\tau}=\frac{\tau(\hat{n}, \sigma)}{|\tau(\hat{n}, \sigma)|}=\hat{s} .
$$



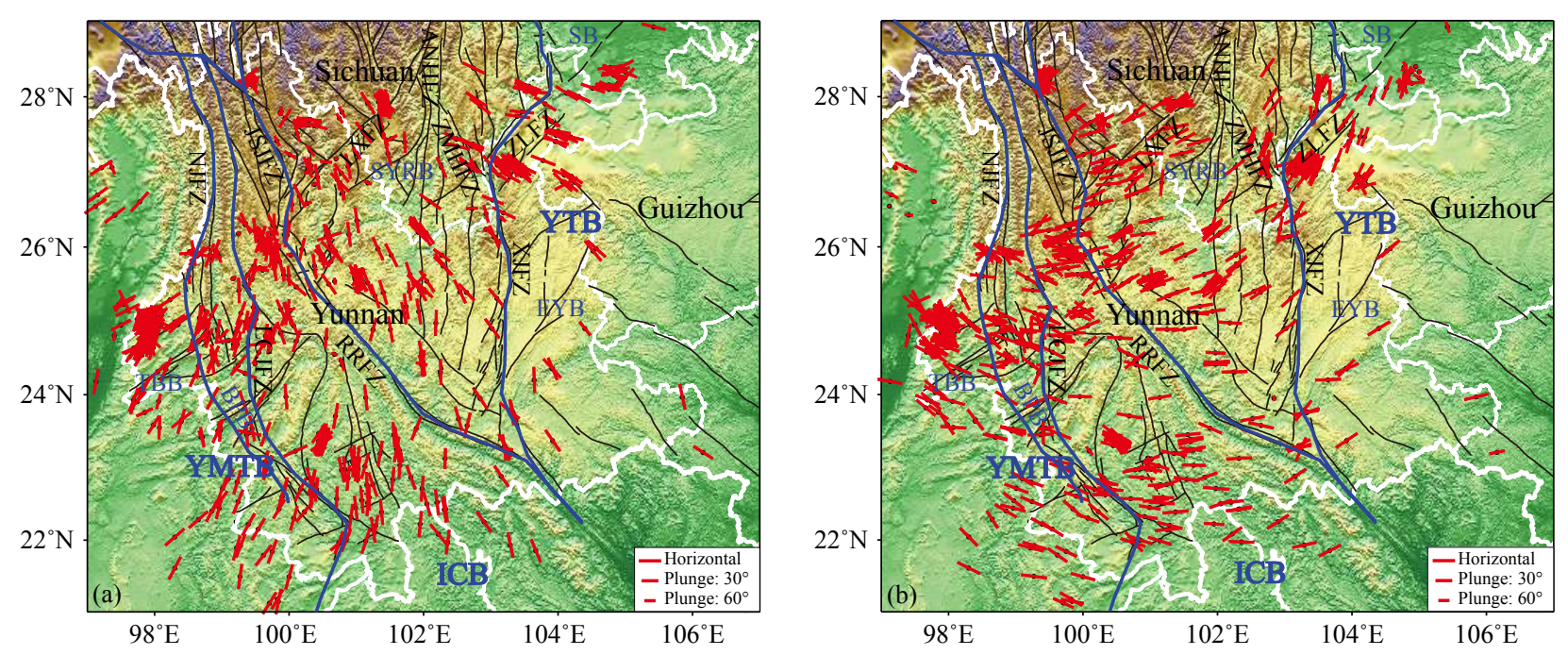

Figure 5. Horizontal projections of the (a) $P$ and (b) T axes of the 707 focal mechanisms in Figure 2. The direction of each line segment represents the azimuth of an axis, whereas the length is proportional to the horizontal projection of the axis (i.e., a longer segment indicates a shallowerdipping axis). The central point of each segment is the epicenter. The abbreviations for the major active tectonic blocks and fault zones are the same as in Figure 1.

In this formula, $\tau(\hat{\boldsymbol{n}}, \boldsymbol{\sigma})$ is the tangential traction on the fault plane with normal $\hat{\boldsymbol{n}}$ in stress tensor $\boldsymbol{\sigma}$, and $\hat{\boldsymbol{s}}$ is the slip direction of an earthquake. The tangential traction in Equation (1) is linearly related to the stress tensor:

$$
\tau(\hat{n}, \sigma)=\sigma \cdot \hat{n}-(\hat{n} \cdot \sigma \cdot \hat{n}) \hat{n} .
$$

Equations (1) and (2) provide a direct link between the stress tensor $\sigma$ we are trying to determine and the observed slip vectors $\hat{\boldsymbol{s}}$ of earthquakes. However, the denominator in equation (1) renders the relation nonlinear. The relation is linearized by an a priori assumption:

$$
|\tau(\hat{n}, \sigma)|=1
$$

which means that we can resolve only the relative amplitude of the deviatoric stress tensor effectively. When studying the spatial and temporal variations of the stress field in a region, the natural approach is to divide the study area into a number of subregions and invert for the stress field of each subregion independently (Hardebeck and Hauksson, 2001). This approach often results in differences in the stress field between adjacent subregions that are difficult to explain. Using the assumption that the crustal stress distribution has a certain continuity, Hardebeck and Michael (2006) proposed a damped regional-scale stress inversion method in which the spatially varying stress field to be resolved is discretized by its values on a regular grid and the inversion is regularized by imposing a smoothing factor, which results in a stress field with the minimum spatial complexity necessary to explain the available earthquake slip data.

In our study, after a number of inversion experiments, we chose to divide the study area into a $0.3^{\circ} \times 0.3^{\circ}$ mesh, and at least eight earthquakes within the $30-\mathrm{km}$ radius of each grid point contributed to the inversion. This resulted in 317 grid points at which the stress field could be resolved by using the 707 focal mechanisms available. After obtaining the stress tensor elements, we calculated the principal stresses $\sigma_{1}, \sigma_{2}, \sigma_{3}\left(\left|\sigma_{1}\right| \geq\left|\sigma_{2}\right| \geq\left|\sigma_{3}\right|\right)$ and their re- spective orientations. The results are displayed in Figure 6.

These results clearly indicate that the entire Yunnan region is largely controlled by a horizontal stress field, with both the maximum and minimum stresses $\sigma_{1}$ and $\sigma_{3}$ nearly horizontal, from the EYB in the east to SYRB and then to the Tengchong-Baoshan Block (TBB) in the west. Both $\sigma_{1}$ and $\sigma_{3}$ have obvious clockwise rotation patterns. The direction of $\sigma_{3}$ in the EYB is north-northeast, especially in the northeastern border area between Yunnan and Sichuan. The predominant direction of $\sigma_{3}$ in SYRB is northeast to east-northeast. After crossing the RRFZ into ICB and YMTB, the $\sigma_{3}$ axis becomes east-west and slightly west-northwest. Note that the directions of the $\sigma_{3}$ and $\sigma_{1}$ axes experience clockwise rotation from north to south. This result is consistent with previous studies (e.g., Xu ZH et al., 1987; Zhao L et al., 2013).

In addition to the Yunnan region being controlled by a horizontal stress field, several pockets have non-strike-slip stress characteristics, such as the normal-faulting stress environment (indicated by the nearly vertical blue line segments) in the Tengchong volcanic area, in the Dêqên-Zhongdian area in northwest Yunnan, near Ninglang, and Huize.

The Tengchong volcanic area (black ellipse in Figure 6) is one of the youngest volcanic regions in Mainland China. About 70 volcanoes of various sizes are distributed in the tensional fissure basin centered around Tengchong. Studies from various disciplines, including geothermal resource exploration, magnetotelluric sounding, and active-source seismology, indicate the presence of magmatic migration channels in the lower crust or upper mantle in the Tengchong area. The normal-faulting earthquakes in this area may be caused by extension because of volcanic activity.

Few previous studies exist on the focal mechanism and stress field in the Dêqên-Zhongdian region (red ellipse in Figure 6) because of the lack of seismicity. The occurrence of the Shangrila-Derong earthquake in 2013 and its aftershocks provided data to study the 


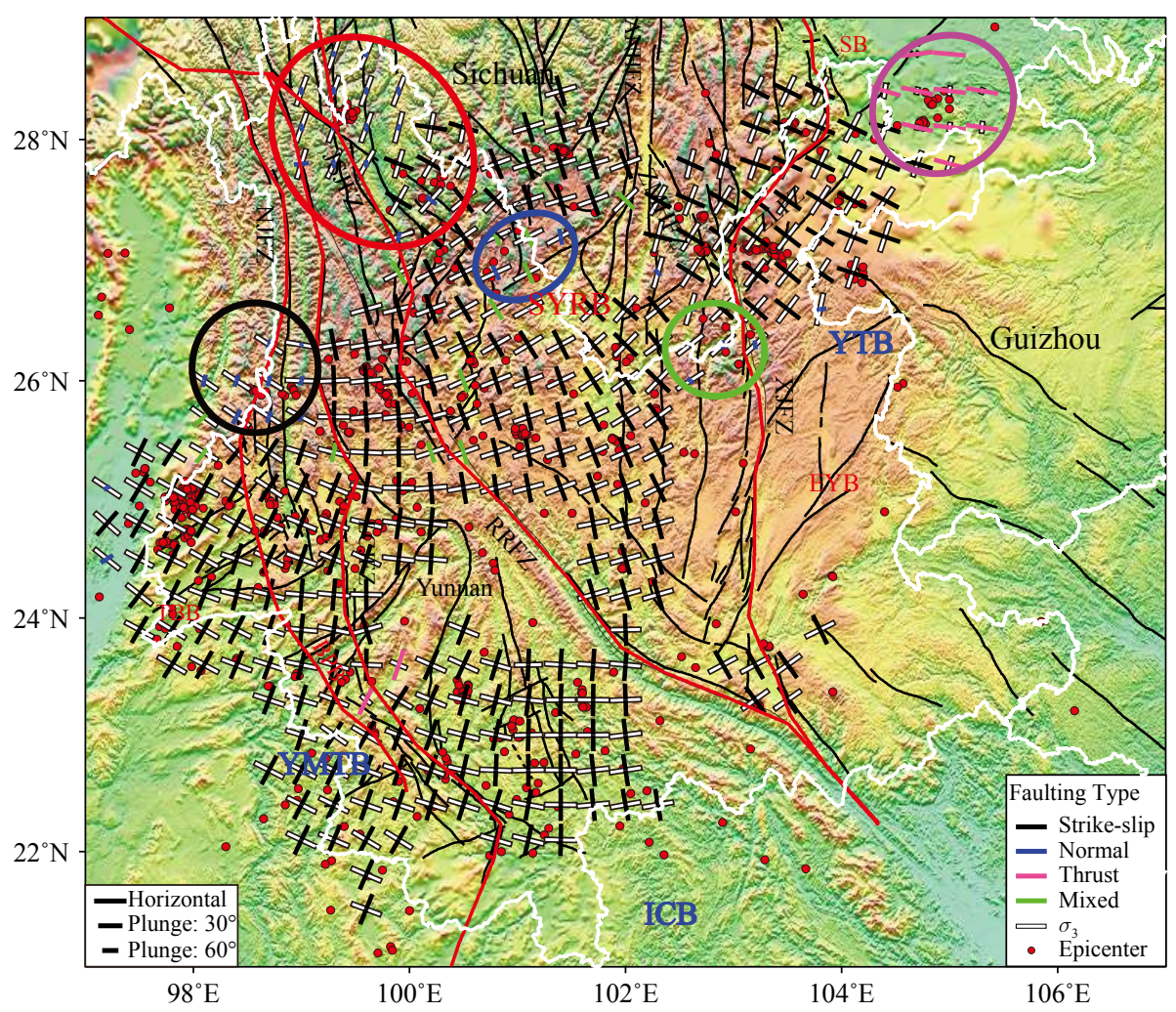

Figure 6. Result of the stress field inversion, with black, blue, magenta, and green line segments depicting the projection of the maximum principal stress axis (maximum compression $\sigma_{1}$ ) and white line segments showing the projection of the minimum principal stress axis (maximum extension $\sigma_{3}$ ). The black, blue, magenta, and green line segments indicate strike-slip, normal-, thrust-, and mixed-type stress environments, respectively. The directions of the line segments show the azimuths of the axes, whereas the lengths indicate the inclinations, with longer line segments showing more horizontal axes. The red dots are epicenters of earthquakes whose focal mechanisms were used in the stress field inversion. Colored ellipses highlight areas with a non-strike-slip stress field, including normal faulting near Tengchong (black), Dêqên-Zhongdian (red), Ninglang (blue), and Huize (green) and thrust faulting at the border between northeastern Yunnan and Sichuan. The abbreviations for the major active tectonic blocks and fault zones are the same as in Figure 1.

focal mechanism and stress field in this region. In both this study and elsewhere, we found that the earthquakes in this area were due to nearly north-south extension, which may have been due to a change in direction of the JSJFZ here from southeast to southsoutheast.

The structure around the Ninglang area (blue ellipse in Figure 6) is complex. A previous study (Hu HX and Gao SY, 1993) suggested that a high-velocity material with a domelike uplift is present below that area. Magma upwellings are usually assumed to occur along the crevices of large and deep-cutting faults, forming a wide range of intrusive dykes at the bottom of the foundation, and the intrusive rocks may continue to fold, leading to upward vertical compression. Therefore, normal-type earthquakes in this area are possibly caused by these vertical compressional stresses.

The Huize area (green ellipse in Figure 6) is located near the eastern boundary of the SYRB, and the left-lateral XJFZ is located here. The GPS (Wang YZ et al., 2008) showed that the left-lateral strikeslip rate of the XJFZ is higher than that of the ZMHFZ. The existence of the normal-faulting earthquakes may be related to the differential slip rate between the north and the south of the fault zones. Finally, reverse faulting can be seen in the border area between northeastern Yunnan and Sichuan, where the $\sigma_{1}$ axis (magenta line segments) is nearly horizontal and $\sigma_{3}$ is almost vertical.

\section{Discussion}

Figure 7 compares the spatial pattern of the principal stress axes in Yunnan determined in this study with published GPS horizontal velocity vectors (Zhao B et al., 2015) and shear-wave polarization directions (Shi YT et al., 2012). From the GPS data, we can see that the horizontal movement is the strongest in northern Yunnan and that it weakens gradually from north to south and from west to east. The pattern of S-wave splitting (red line segments in Figure 7a) does not seem to correspond to the stress orientation, whereas the fast axes of the SKS waves (red line segments in Figure $7 \mathrm{~b}$ ) show good correlation with the direction of the extensional stress axis $\sigma_{1}$ except for the regions with normal-faulting stress, such as around Dêqên-Zhongdian (red ellipse in Figure 7b) and Huize (green ellipse).

In the EYB, the result of stress field inversion shows that the predominant direction of the $\sigma_{3}$ axis is in the north-northeast direction and that the $\sigma_{1}$ axis is in the northwest direction. This result is consistent with the stress direction of the YTB, which is influenced by the eastward movement of the Tibetan Plateau. The GPS 
velocity field (Figure 7a) shows that the block moves in a southeast direction and that the velocity of the YTB is much slower than that of the SYRB. Sun YJ et al. (2017) calculated that the horizontal velocity of EYB is $\sim 7.67 \mathrm{~mm} / \mathrm{a}$. In comparison with SYRB, the velocity of EYB is reduced by nearly $50 \%$, indicating that the ANHFZ, ZMHFZ, and XJFZ serve as a buffer zone between the fast-moving SYRB in the west and the more stable EYB in the east.

The SYRB is bounded by the XJFZ on the east and the RRFZ and JSJFZ on the west. Along the Longmenshan Fault Zone to the north of the study region, where the $2008 M_{w} 7.9$ Wenchuan earthquake occurred, the eastward movement of the high Tibetan Plateau is resisted by the YTB, resulting in the southeastward extrusion of the SYRB. Our stress inversion result showed that the stress field in the SYRB is complex. Besides the typical strike-slip environment, several normal or extensional stress conditions exist (e.g., near Ninglang and Huize marked by blue and green ellipses, respectively, in Figure 7). Along the LXFZ, the $\sigma_{1}$ axis is northwest, whereas the $\sigma_{3}$ axis is northeast. More earthquakes were used in the present study in the Dêqên-Zhongdian area than were used by Zhao L et al. (2013), resulting in a more robust and better resolved stress field. Xu ZG et al. (2016) found that in the stress field in the Dêqên-Zhongdian area between $27^{\circ} \mathrm{N}$ and $29^{\circ} \mathrm{N}$, the $\sigma_{3}$ axis is nearly east-west and that $\sigma_{1}$ is nearly northsouth. However, in our result, the $\sigma_{3}$ axis changed gradually from north-northwest to northwest, whereas the more vertical $\sigma_{1}$ axis changed direction from north-northeast to northeast moving from north to south. The larger number of earthquake focal mechanisms available in this study enabled us to better resolve the spatial variation in the stress field. The GPS velocity field (Figure 7a) showed that the SYRB moves in the southeast direction, which corresponds well to the direction of the compressional stress axis. The southeastward escape of the SYRB is quite clear from the GPS data, which shows a more rapid velocity of SYRB than the sur- rounding regions. This result was also confirmed by the right-lateral focal mechanisms of earthquakes along the RRFZ and the leftlateral ones along the XJFZ.

The ICB is bordered by the RRFZ in the east and the LCJFZ in the west. The block is still dominated by a strike-slip stress regime with horizontally oriented $\sigma_{1}$ and $\sigma_{3}$ axes. From north to south, the extensional $\sigma_{3}$ axis gradually changes from east-west to eastsoutheast, whereas the compressional $\sigma_{1}$ axis changes from north-south to north-northeast. This result is consistent with the reports of Zhao L et al. (2013) and Xu ZG et al. (2016). The GPS velocity field (Figure 7a) showed the block moving in a nearly southward direction, in line with the direction of the maximum compressional stress.

The BSB is an elongated region west of the ICB just across the LCJFZ. Crisscrossing faults in this block trend in the north-northwest and northeast directions, resulting in a checkerboard formation with a high level of seismic activity. Our inversion results showed that the $\sigma_{3}$ axis is in the northwest direction and the $\sigma_{1}$ axis is in the north-northeast direction, again in agreement with previous studies (Zhao L et al., 2013; Xu ZG et al., 2016; Sun YJ et al., 2017). The GPS velocity field (Figure 7a) showed that the movement of this block is in a south-southeast direction. Sun YJ et al. (2017) pointed out that the horizontal velocity of the block is $7.72 \mathrm{~mm} / \mathrm{a}$ and that the velocity is reduced by $55 \%$ in comparison with the SYRB. This result suggests that the RRFZ has accommodated a significant amount of the movement of the SYRB. This movement has also changed the direction of the stress field and the horizontal GPS velocity field from the SYRB to the BSB.

The TBB is located inside the YMTB to the west of the NJFZ. The main geologic feature in this block is the Tengchong volcanic belt. The inversion results showed a stress field less dominated by strike-slip faulting in the block, with a northwest-oriented $\sigma_{3}$ axis

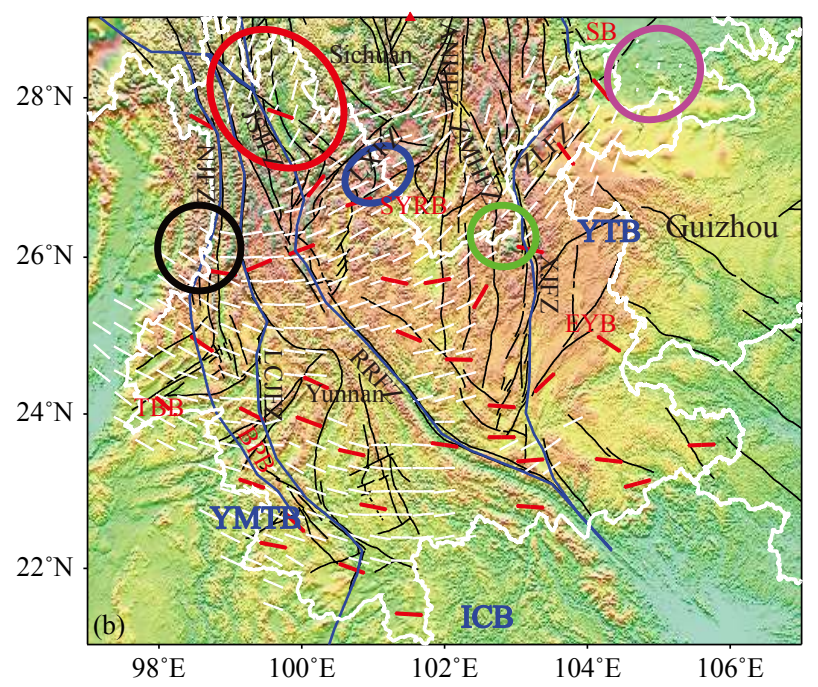

Figure 7. (a) Comparison of the maximum compression axis $\sigma_{1}$ (white line segments) with the GPS velocity field from 1999 to 2014 under the stable Eurasian reference frame (black arrows; Zhao et al., 2015) and symmetry axis of anisotropy (red line segments) obtained from shear-wave (S) splitting (Shi YT et al., 2012). (b) Comparison of the maximum extension axis $\sigma_{3}$ (white line segments) with the symmetry axis of anisotropy (red line segments) obtained from shear-wave (SKS) splitting (Shi YT et al., 2012). Colored ellipses are the same as in Figure 6. The abbreviations for the major active tectonic blocks and fault zones are the same as in Figure 1. 
and a more vertically oriented north-northeast $\sigma_{1}$ axis. A strong normal-faulting stress environment is present in the Tengchong volcanic belt, which has a horizontal extensional axis and a nearly upright $\sigma_{1}$ axis. This feature is consistent with the report by Zhao $\mathrm{L}$ et al. (2013). However, Xu ZG et al. (2016) showed that the Tengchong volcanic zone is still in a strike-slip stress field, which is quite different from the results of Zhao L et al. (2013) and in this study. Finally, the GPS velocity field (Figure 7a) showed that the block moves in a southwest direction, in line with the direction of maximum compression in this region.

The stress field inversion result obtained in this study is generally in good agreement with previously published results (e.g., Zhao L et al., 2013; Xu ZG et al., 2016). The overall strike-slip stress pattern in Yunnan is quite consistently resolved in all studies. The normal-faulting features around the Tengchong volcanic area and near Huize, marked by the red and green ellipses in Figures 6 and 7, were also reported by Zhao L et al. (2013). However, Xu ZG et al. (2016) obtained a strike-slip stress pattern around Tengchong and Huize that is difficult to reconcile with the fact that earthquake focal mechanisms in those two areas are predominantly normal, clearly indicating a normal-faulting local stress status.

The results of the regional tectonic stress field obtained in this study are also consistent with results for the GPS surface velocity field, especially in SYRB, where the direction of the maximum compressional stress is parallel to the GPS velocity field (Figure 7a). The polarization directions of the fast waves obtained from Swave splitting (red line segments in Figure 7a) had no clear relationship with the orientations of the principal stress axes. The main reason for this may be that Shi YT et al. (2012) analyzed the polarization directions of the fast waves by using S-waves from local crustal earthquakes, which mainly reflect localized anisotropy of complex origins in the upper crust. As the authors pointed out, the direction of the fast local S-wave is generally parallel to the local compressional stress. However, because of the influence of the complex fault distribution and geologic structure, the direction of the fast local S-wave is highly variable. The stress axis orientations obtained in this study are more indicative of regionalscale tectonic interactions. In fact, the fast axis directions obtained from SKS splitting in Figure 7b, which may be indicative of anisotropy induced by regional extension, athenospheric flow, or both, show good agreement with the orientation of the maximum extensional axis, suggesting that the stress field pattern obtained here from inversion of the earthquake focal mechanisms is robust.

\section{Conclusion}

In this study, we determined the focal mechanism solutions of 627 moderate and small earthquakes in Yunnan by using the CAP method. These focal mechanism solutions were combined with solutions of 80 additional earthquakes to invert for spatial variations in the orientations of the regional stress field. The following observations were made from our inversion results:

(1) The focal mechanisms of earthquakes in Yunnan are mostly strike-slip, with a small number of normal events distributed in several locales with volcanic activity or crisscrossing active fault zones. Earthquakes with significant thrust components are also present in northeast Yunnan bordering Sichuan. A significant majority of the earthquakes occur in the top $10 \mathrm{~km}$ of the crust.

(2) The overall stress environment in Yunnan is strike-slip, with both maximum and minimum stress axes being horizontal. The maximum compression is primarily in the northwest-southeast direction because of the tectonic stresses imposed on the region by the Tibetan Plateau from the northwest and by the YTB from the east. The eastern Yunnan region acts as a buffer zone, resulting in a largely east-west-oriented maximum extensional stress. The direction of maximum compression experiences a clockwise rotation, with a northwest-southeast orientation in northern Yunnan to nearly north-south in central Yunnan and slightly northeast-southeast in southwestern Yunnan.

(3) The direction of maximum compression in Yunnan is in good agreement with the direction of GPS velocity, whereas the direction of maximum extension is consistent with the fast axis direction obtained from SKS splitting. The agreement of spatial patterns obtained from independent geophysical observations suggests that the stress inversion results obtained in this study are robust and that the controlling factor in the stress field in Yunnan is the response of the SYRB to the tectonic force from the Tibetan Plateau and YTB.

\section{Acknowledgments (Data and Resources)}

Broadband records for the events used in this study are available from the author (Y. Luo). The earthquake catalog can be obtained from the China Earthquake Data Center (CEDC) at http://data. earthquake.cn/index.html (last accessed January 2019). The opensource software package CAP for focal mechanism determination was written by L. Zhu and can be downloaded at http://www.eas. slu.edu/People/LZhu/downloads/gCAP3D1.0.tar. The stress inversion software SATSI was developed by J. L. Hardebeck and A. J. Michael and is available for download from the U.S. Geological Survey software website (http://earthquake.usgs.gov/research/software/, last accessed January 2019). The Global CMT solutions were obtained from http://www.globalcmt.org(last accessed January 2019). All figures in this manuscript were produced with the Generic Mapping Tools (GMT) of Wessel and Smith (1998).

This work was supported by the Basic Research Fund of the Institute of Earthquake Forecasting, China Earthquake Administration (2015IES010302), and the State Key Laboratory of Geodesy and Earth's Dynamics, Institute of Geodesy and Geophysics, Chinese Academy of Sciences (SKLGED2018-4-3-E). We thank the two anonymous reviewers for their constructive comments.

\section{References}

Angelier, J. (1979). Determination of the mean principal directions of stresses for a given fault population. Tectonophysics, 56(3-4), T17-T26. https://doi.org/10.1016/0040-1951(79)90081-7

Angelier, J. (1984). Tectonic analysis of fault slip data sets. J. Geophys. Res. Solid Earth, 89(B7), 5835-5848. https://doi.org/10.1029/JB089iB07p05835

Gephart, J. W., and Forsyth, D. W. (1984). An improved method for determining the regional stress tensor using earthquake focal mechanism data: Application to the San Fernando earthquake sequence. J. Geophys. Res. Solid Earth, 89(B11), 9305-9320. https://doi.org/10.1029/JB089iB11 p09305 
Hardebeck, J. L., and Hauksson, E. (2001). Crustal stress field in southern California and its implications for fault mechanics. J. Geophys. Res. Solid Earth, 106(B10), 21859-21882. https://doi.org/10.1029/2001JB000292

Hardebeck, J. L., and Michael, A. J. (2006). Damped regional-scale stress inversions: Methodology and examples for southern California and the Coalinga aftershock sequence. J. Geophys. Res. Solid Earth, 111(B11), B11310. https://doi.org/10.1029/2005JB004144

Hu, H. X., and Gao, S. Y. (1993). The investigation of fine velocity structure of the basement layer of earth's crust in western Yunnan region. Earthq. Res. China (in Chinese), 9(4), 354-363.

Huang, F. G., Chen, Y., Qin, J. Z., Li, Z. H., An, X. W., and Yang, Z. S. (2010). The Seismicity in Yunnan (in Chinese). Kunming: Yunnan Science and Technology Press.

Lü, J., Zheng, Y., Ni, S. D., and Gao, J. H. (2008). Focal mechanisms and seismogenic structures of the $M_{\mathrm{s}} 5.7$ and $M_{\mathrm{s}} 4.8$ Jiujiang-Ruichang earthquakes of Nov. 26, 2005. Chinese J. Geophys. (in Chinese), 51(1), 158-164. https://doi.org/10.3321/j.issn:0001-5733.2008.01.020

Long, F., Zhang, Y. J., Wen, X. Z., Ni, S. D., and Zhang, Z. W. (2010). Focal mechanism solutions of $M_{\mathrm{L}} \geq 4.0$ events in the $M_{\mathrm{s}} 6.1$ Panzhihua-Huili earthquake sequence of Aug 30, 2008. Chinese J. Geophys. (in Chinese), 53(12), 2852-2860. https://doi.org/10.3969/j.issn.0001-5733.2010.12.008

Luo, J., Zhao, C. P., Lü, J., Zhou, L. Q., and Zheng, S. H. (2016). Characteristics of focal mechanisms and the stress field in the Southeastern Margin of the Tibetan Plateau. Pure Appl. Geophys., 173(8), 2687-2710. https://doi.org/10.1007/s00024-016-1350-8

Luo, Y., Ni, S. D., Zeng, X. F., Zhen, Y., Chen, Q. F., and Chen, Y. (2010). A shallow aftershock sequence in the north-eastern end of the Wenchuan earthquake aftershock zone. Sci. China Earth Sci., 53(11), 1655-1664. https://doi.org/10.1007/s11430-010-4026-8

McKenzie, D. P. (1969). The relation between fault plane solutions for earthquakes and the directions of the principal stresses. Bull. Seismol. Soc. Am., 59(2), 591-601.

Michael, A. J. (1984). Determination of stress from slip data: Faults and folds. J. Geophys. Res. Solid Earth, 89(B13), 11517-11526. https://doi.org/10.1029/JB089iB13p11517

Michael, A. J. (1987). Use of focal mechanisms to determine stress: A control study. J. Geophys. Res. Solid Earth, 92(B1), 357-368. https://doi.org/10.1029/JB092iB01p00357

Qian, X. D., Qin, J. Z., and Liu, L. F. (2011). Study on recent tectonic stress field in Yunnan region. Seismol. Geol. (in Chinese), 33(1), 91-106. https://doi.org/10.3969/j.issn.0253-4967.2011.01.009

Qiao, X. J., Wang, Q., and Du, R. L. (2004). Characteristics of current crustal deformation of active blocks in the Sichuan-Yunnan region. Chinese J. Geophys. (in Chinese), 47(5), 805-811. https://doi.org/10.3321/j.issn:00015733.2004.05.011

Shen, C. Y., Wu, Y., Wang, Q., You, X. Z., and Qiao, X. J. (2002). GPS data inversion of kinematic model of main faults in Yunnan. J. Geodesy Geodyn. (in Chinese), 22(3), 46-51. https://doi.org/10.3969/j.issn.1671-5942.2002.03.009

Shi, Y. T., Gao, Y., Su, Y. J., and Wang, Q. (2012). Shear-wave splitting beneath Yunnan area of Southwest China. Earthq. Sci., 25(1), 25-34. https://doi.org/10.1007/s11589-012-0828-4
Sun, Y. J., Zhao, X. Y., Huang, Y., Yang, H., and Li, F. (2017). Characteristics of focal mechanisms and stress field of Yunnan area. Seismol. Geol. (in Chinese), 39(2), 390-407. https://doi.org/10.3969/j.issn.0253-4967.2017.02.009

Wang, L. L., Wang, Q. H., Zhang, Y., and Wang, Y. (2016). Analysis of current activity of main faults in Yunnan region based on GPS. J. Inst. Dis. Prev. (in Chinese), 18(1), 1-8. https://doi.org/10.3969/j.issn.1673-8047.2016.01.001

Wang, Y. Z., Wang, E. N., Shen, Z. K., Wang, M., Gai, W. J., Qiao, X. J., Meng, G. J., Li, T. M., Tao, W., ... Li, P. (2008). GPS-constrained inversion of present-day slip rates along major faults of the Sichuan-Yunnan region, China. Sci. China Ser. D Earth Sci., 51(9), 1267-1283. https://doi.org/10.1007/s11430-0080106-4

Wessel, P., and Smith, W. H. F. (1998). New, improved version of the Generic Mapping Tools released, EOS Trans. AGU, 79, 579.

Wu, J. P., Ming, Y. H., and Wang, C. Y. (2004). Source mechanism of small-tomoderate earthquakes and tectonic stress field in Yunnan province. Acta Seismol. Sin. (in Chinese), 26(5), 457-465. https://doi.org/10.3321/j.issn:02533782.2004.05.001

Xie, F. R., Zhu, J. Z., Liang, H. Q., and Liu, G. X. (1993). Basic features of modern tectonic stress field in Southwest China. Acta Seismol. Sin. (in Chinese), 15(4), 407-417.

Xu, Z. G., Huang, Z. C., Wang, L. S., Xu, M. J., Ding, Z. F., Wang, P., Mi, N., Yu, D. Y., and Li, H. (2016). Crustal stress field in Yunnan: Implications for crust-mantle coupling. Earthq. Sci., 29(2), 105-115. https://doi.org/10.1007/s11589-0160146-3

Xu, Z. H., Wang, S. Y., Huang, Y. R., Gao, A. J., Jin, X. F., and Chang, X. D. (1987). Directions of mean stress axes in southwestern China deduced from microearthquake data. Acta Geophys. Sin. (in Chinese), 30(5), 476-486.

Zhao, B., Huang, Y., Zhang, C. H., Wang, W., Tan, K., and Du, R. L. (2015). Crustal deformation on the Chinese mainland during 1998-2014 based on GPS data. Geodesy Geodyn., 6(1), 7-15. https://doi.org/10.1016/j.geog.2014.12.006

Zhao, L., Luo, Y., Liu, T., and Luo, Y. (2013). Earthquake focal mechanisms in Yunnan and their inference on the regional stress field. Bull. Seismol. Soc. Am., 103(4), 2498-2507. https://doi.org/10.1785/0120120309

Zhao, L. S., and Helmberger, D. V. (1994). Source estimation from broadband regional seismograms. Bull. Seismol. Soc. Am., 84(1), 91-104.

Zheng, Y., Ma, H. S., Lü, J., Ni, S. D., Li, Y. C., and Wei, S. J. (2009). Source mechanism of strong aftershocks $\left(M_{S} \geq 5.6\right)$ of the 2008/05/12 Wenchuan earthquake and the implication for seismotectonics. Sci. China Ser. D: Earth Sci., 52(6), 739-753. https://doi.org/10.1007/s11430-009-0074-3

Zhong, J. M., and Cheng, W. Z. (2006). Determination of directions of the mean stress field in Sichuan-Yunnan region from a number of focal mechanism solutions. Acta Seismol. Sin. (in Chinese), 28(4), 337-346. https://doi.org/10.3321/j.issn:0253-3782.2006.04.001

Zhu, L. P., and Helmberger, D. V. (1996). Advancement in source estimation techniques using broadband regional seismograms. Bull. Seismol. Soc. Am., 86(5), 1634-1641.

Zhu, L. P., and Ben-Zion, Y. (2013). Parametrization of general seismic potency and moment tensors for source inversion of seismic waveform data. Geophys. J. Int., 194(2), 839-843. https://doi.org/10.1093/gji/ggt137 